\title{
Photolysis of dicamba (3,6-dichloro-2-methoxybenzoic acid) in aqueous solution and dispersed on solid supports
}

\author{
Jean-Pierre Aguer, ${ }^{1, \dagger}$ Frédéric Blachère, ${ }^{1}$ Pierre Boule, ${ }^{1}$ Sandrine Garaudee, ${ }^{2}$ and \\ Chantal Guillard ${ }^{2}$ \\ ${ }^{1}$ Laboratoire de Photochimie Moléculaire et Macromoléculaire, UMR-CNRS 6505, F-63177 Aubière Cedex, France \\ ${ }^{2}$ Laboratoire de Photocatalyse, Catalyse et Environnement, Ecole Centrale de Lyon, BP 163, F-69131 Ecully Cedex, France
}

\begin{abstract}
Dicamba (3,6-dichloro-2-methoxybenzoic acid) was exposed to UV light in aqueous solution. It was also irradiated in the solid phase without support or adsorbed on laponite (a synthetic clay) and ferric oxide.

Two main photoproducts (1) and (2) were identified in irradiated aqueous solutions. Both involve the substitution of chlorine by $\mathrm{OH}$. The unexpected product (2) is formed through a kinetic reaction of primary product; it results from an oxidation and it is not formed in the absence of oxygen.
\end{abstract}<smiles>COc1c(Cl)ccc(Cl)c1C(=O)O</smiles>

dicamba<smiles>COc1c(O)ccc(O)c1C(=O)O</smiles>

$(1)$<smiles>O=C1OCOc2c(O)ccc(O)c21</smiles>

(2)

A huge number of intermediate products were simultaneously formed when dicamba is irradiated in the solid phase in presence of laponite. They correspond to methylation, decarboxylation, chlorination, dechlorination, and hydroxylation reactions. The latter is probably due to the presence of water in clays, whereas methylation, chlorination and decarboxylation have been attributed to the cage effect and to an energy transfer process. Without support or with ferric oxide, no decarboxylation occurs. The nature of the inorganic support also modify the kinetics of dicamba photolysis.

\section{INTRODUCTION}

Dicamba (3,6-dichloro-2-methoxybenzoic acid) is a selective systemic herbicide used for the control of perennial broad leafed weeds in corn, small grains, sugar cane, and turf [1]. It is resistant to oxidation and hydrolysis under normal conditions, stable in acids and alkalies. Dicamba can be applied to leaves or soil and can reach surface water through runoff events. The solubility of dicamba in unbuffered solution was reported to be $6.5 \mathrm{~g} \cdot \mathrm{L}^{-1}$ and the pKa 1.87 [1] or 1.94 [2]. The biodegradation and the photodegradation are the two main pathways for the elimination of pollutants from the environment. In soil biodegradation is the main way for pesticide transformation. Many publications deal with the biodegradation of dicamba, for example $[2,3$, 4]. The main metabolite is 3,6-dichlorosalicylic acid, but the formations of 2,5-dihydroxy-3,6-dichlorobenzoic acid and little amounts of 5-hydroxydicamba were also reported [3].

The phototransformation of dicamba was not so much studied. To our knowledge the main work about it was carried out by Bourgine et al. and deals with the industrial photochemical elimination of several

\footnotetext{
† To whom correspondence should be addressed.
}

herbicides [5]. It was concluded that dicamba can be photodegradated, but much slower than some other herbicides such as mecoprop and MCPA. Photoproducts were not analysed.

It may be noted that the main photochemical process in the phototransformation of chloro- and dichlorobenzenes is photohydrolysis of a $\mathrm{C}-\mathrm{Cl}$ bond [6] and that the photolysis of 4-chlorophenol in air-saturated solution leads to the formation of benzoquinone $[7,8]$ via the formation of a carbene [9, 10].

The aim of the present work is to carry out a kinetic and analytical study of the photochemical transformation of dicamba in water and dispersed on inorganic supports, since the presence of water is assumed to play an important role in the orientation of the reaction.

\section{MATERIALS AND METHODS}

\subsection{Reactants. Dicamba was provided by Chem Service.}

Water was purified with Milli-Q device (Millipore) and its purity was controlled by its resistivity $(>18 \mathrm{M} \Omega \cdot \mathrm{cm})$. In some cases solutions were deoxygenated by bubbling nitrogen for $15 \mathrm{~min}$. 
Sylilating agent was BSTFA + 1\%TMCS provided by Pierce whereas diazomethane was prepared from N-methyl nitrosotoluene-4-sulphonamine (Prolabo), $\mathrm{KOH}$, methanol and diethylether.

\subsection{Procedure and irradiation.}

Photolysis in aqueous solution. Aqueous solutions $\left(5 \mathrm{ml}, 2 \times 10^{-4} \mathrm{~mol} \cdot \mathrm{L}^{-1}\right)$ were irradiated with six fluorescent lamps (Duke Sunlamp GL20) emitting between 275 and $350 \mathrm{~nm}$ with a maximum emission at $310 \mathrm{~nm}$ in a cylindrical quartz cell located on the axis of a cylindrical mirror. The quantum yield at $275 \mathrm{~nm}$ was measured by using a monochromator Schoeffel equipped with a high-pressure xenon lamp. The beam was parallel and the reactor was a square quartz cuvette with a $1 \mathrm{~cm}$ path length. The incident flow intensity at this wavelength was evaluated as $3.7 \times$ $10^{14}$ photons $\cdot \mathrm{s}^{-1} \cdot \mathrm{cm}^{-3}$ by ferrioxalate actinometry. After irradiation, each compound was either analysed directly by HPLC/UV or isolated by preparative HPLC and analysed by GC/MS without derivatisation or after esterification with diazomethane or silylation. For silylation reaction, $200 \mu \mathrm{L}$ of BSTFA $1 \%$ TMCS and $200 \mu \mathrm{L}$ of diethylether were added to extract compound and was held for 10 minutes under stirring.

Esterification was realized by using $500 \mu \mathrm{L}$ of freshly prepared diazomethane and stirring for 30 minutes in the dark.

Photolysis in adsorbed phase. Dicamba $(5 \mathrm{mg})$ adsorbed on laponite or the pure solid $(50 \mathrm{mg})$, was dispersed on the bottom of a Pyrex reactor and irradiated with a Philips HPK $125 \mathrm{~W}$ high pressure mercury lamp through a $2.2 \mathrm{~cm}$ thick circulating water filter. The wavelengths imposed on the substrate ranged between $290 \mathrm{~nm}$ and $575 \mathrm{~nm}$ with a maximum at $360 \mathrm{~nm}$. After irradiation, intermediate products were analysed by HPLC/UV with $\mathrm{MeOH} /$ Water (50/50 by volume) as eluent after ultrasonic extraction ( $5 \mathrm{~min}$ ) and by GC-MS applying ethyl acetate or diethylether extraction.
2.3. Analyses. Absorption spectra were recorded on a Cary $13 \mathrm{C}$ (Varian) spectrophotometer.

HPLC analyses of solutions were performed on a Merck chromatograph or on a Waters 990 chromatograph equipped with a photodiode array detector. The column was a Hewlett Packard reverse-phase $\mathrm{C}_{18}, 5 \mu \mathrm{m}$ $(250 \mathrm{~mm} \times 4.6 \mathrm{~mm})$, with $\mathrm{MeOH} /$ Water $(55 / 45$ by volume) as the eluent. Preparative HPLC was carried out on a Gilson chromatograph with a Microsorb $\mathrm{C}_{18}$ column, $3 \mu \mathrm{m}(100 \mathrm{~mm} \times 20 \mathrm{~mm})$. In case of the irradiations of the pure solid, a gradient was also used: acidified water $\mathrm{pH}=3 / \mathrm{MeOH}(75 / 25$ by volume) during $12 \mathrm{~min}$, then $50 / 50$ at $60 \mathrm{~min}$ and $10 / 90$ at $90 \mathrm{~min}$.

$\left[{ }^{1} \mathrm{H}\right]$ NMR spectra were recorded on Bruker AC $400 \mathrm{MHz}$ Fourier transform spectrometer.

GC/MS analyses were obtained on a HP 5890 series II gas chromatograph equipped with a HP 5971 mass detector. The mass analyser was operated in the electron impact mode (EI). The GC column was a chrompack CPSil 5CB and the temperature program depended on the compound to be analysed. For underivatized solution: injector: $473 \mathrm{~K}$; column $373 \mathrm{~K}, 373 \mathrm{~K}-473 \mathrm{~K}\left(6 \mathrm{~K} \cdot \mathrm{min}^{-1}\right.$, hold: $30 \mathrm{~min}$ ); detector: $523 \mathrm{~K}$ were used. For diazomethane derivatized products: injector: $543 \mathrm{~K}$; column: $313 \mathrm{~K}$ (hold: $5 \mathrm{~min}), 313 \mathrm{~K}-573 \mathrm{~K}\left(10 \mathrm{~K} \cdot \mathrm{min}^{-1}\right.$; hold: $30 \mathrm{~min}$ ); detector: $573 \mathrm{~K}$ were applied. For silylated products: injector: $473 \mathrm{~K}$; column $393 \mathrm{~K}$ (hold: $4 \mathrm{~min}$ ); $393 \mathrm{~K}-473 \mathrm{~K}\left(3 \mathrm{~K} \cdot \mathrm{min}^{-1}\right.$ hold: $\left.30 \mathrm{~min}\right)$; detector: $573 \mathrm{~K}$ were used.

FTIR spectra were recorded on a Bruker Vector 22 by using $\mathrm{KBr}$ pellet ( $4 \mathrm{mg}$ of sample and $297 \mathrm{mg}$ of $\mathrm{KBr}$ were pressed under $\left.3 \mathrm{t} \cdot \mathrm{cm}^{-2}\right)$.

Gas phase analyses were performed on a Mass Spectrum Transpector 2.0 Inficon.

\section{RESULTS}

3.1. Physico-chemical properties. From the pKa values given in the literature [1, 2] the anionic form is dominant in natural waters or unbuffered solutions.<smiles>COc1c(Cl)ccc(Cl)c1C(=O)O</smiles>

$\overrightarrow{p k_{a}=(1.87 \text { or } 1.94)}$<smiles>COc1c(Cl)ccc(Cl)c1C(=O)[O-]</smiles>

The neutral form of dicamba absorbs at wavelengths shorter than $325 \mathrm{~nm}$ with a maximun located at $275 \mathrm{~nm}$. The molar absorption coefficient at this wavelength was evaluated as $500 \mathrm{M}^{-1} \mathrm{~cm}^{-1}$. As it can be seen in Figure 1 the protonated form is significantly more absorbing and its maximum is located at longer wavelengths. Aqueous solutions were stable in the dark: no change was observed in the UV-Visible spectrum after $24 \mathrm{~h}$ at room temperature.

The following values were obtained for the $\left[{ }^{1} \mathrm{H}\right] \mathrm{NMR}$ spectrum of dicamba in $\mathrm{CDCl}_{3}: \delta(\mathrm{ppm}) ; 4.05\left(\mathrm{~s}, \mathrm{CH}_{3}\right)$ $7.15\left(\mathrm{~d}, \mathrm{H}_{4}\right.$ or $\left.\mathrm{H}_{5}, \mathrm{~J}=7 \mathrm{~Hz}\right), 7.40\left(\mathrm{~d}, \mathrm{H}_{5}\right.$ or $\left.\mathrm{H}_{4}, \mathrm{~J}=7 \mathrm{~Hz}\right)$, 10.80 (s, $\mathrm{COOH})$.

When dicamba was in the solid state direcly in reactor or dispersed on clay, FTIR analysis showed that the anionic form is also the dominant form in the presence of clay (strong asymetric vibration of $\mathrm{COO}^{-}$ at $1630-1550 \mathrm{~cm}^{-1}$; symetric vibration of $\mathrm{COO}^{-}$at $1440 \mathrm{~cm}^{-1}$ ) while dimeric form is present if dicamba is not adsorbed on solid (stretching $(\mathrm{C}=\mathrm{O})$ at $1313 \mathrm{~cm}^{-1}$; 
$(\mathrm{OH})$ of $\mathrm{COOH}$ at $1288 \mathrm{~cm}^{-1}$; stretching $(\mathrm{C}-\mathrm{O})$ at 1184 and $1388 \mathrm{~cm}^{-1}$ ). In presence of ferric oxide, dicamba is present as a mixture of anionic and dimeric forms.

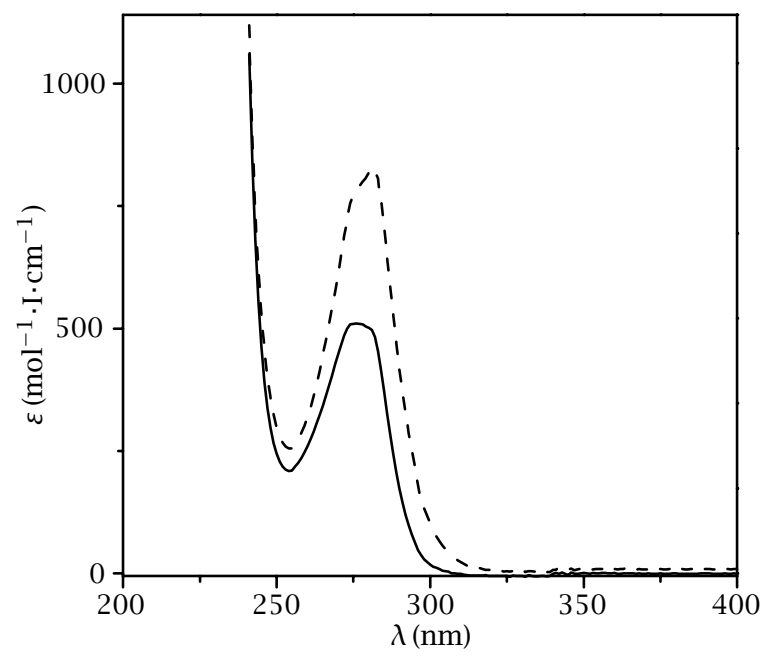

Figure 1. UV absorption spectrum of an aqueous solution of dicamba: - basic or neutral solutions, - - - acidic solution

\subsection{Dicamba photolysis in aqueous solution.}

Quantum yield measurement and evolution of $U V$ spectrum. The quantum yield of disappearance of dicamba was evaluated at $2.15 \times 10^{-2}$ in aerated solution irradiated at $275 \mathrm{~nm}$.

A significant change was observed in the UV absorption when an air-saturated aqueous solution of dicamba $\left(2 \times 10^{-4} \mathrm{M}\right)$ in pure water at natural $\mathrm{pH}$ was irradiated within the range 275 and $350 \mathrm{~nm}$. An increase of absorbance was observed within the whole spectrum. A new band appears between 300 and $350 \mathrm{~nm}$ (Figure 2). Two main photoproducts (1) and (2) were detected by HPLC chromatography (detection at $275 \mathrm{~nm}$ ). Both have shorter retention time than dicamba. (1) is a primary photoproduct and its formation is unaffected by oxygen. Product (2) is produced through kinetics of the primary photoproduct, but its formation needs the presence of oxygen. It was observed that (2) does not result from the photooxydation of (1).

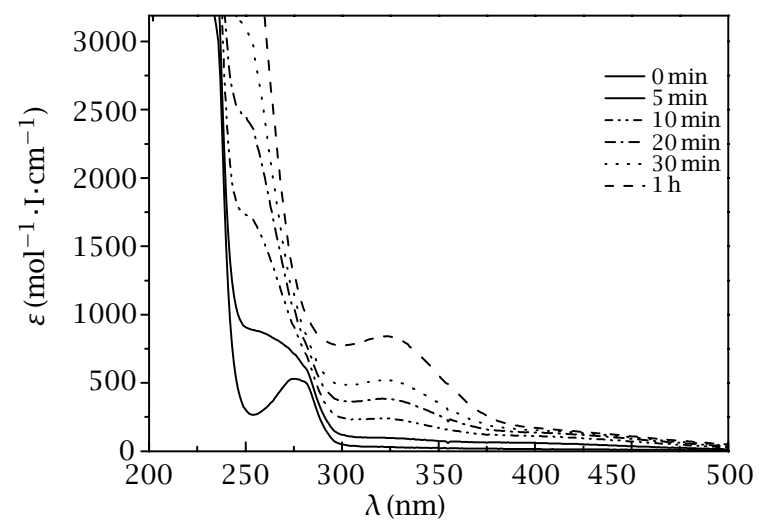

Figure 2. Evolution of the UV spectrum of an air-saturated solution of dicamba $\left(2 \times 10^{-4} M\right)$ irradiated between 275 and $350 \mathrm{~nm}$.
The UV spectra of (1) and (2) are similar and quite different from the spectrum of dicamba. Both products present a strong absorption band between 300 and $400 \mathrm{~nm}$ with maxima located near 340 and $350 \mathrm{~nm}$, respectively.

Identification of photoproducts. Products (1) and (2) were isolated by preparative HPLC chromatography. Results of mass spectrometry and $\left[{ }^{1} \mathrm{H}\right]$ NMR shifts in deuterochloroform are gathered below:

Product (1)

$\left[{ }^{1} \mathrm{H}\right] \mathrm{NMR} \delta(\mathrm{ppm}): 4.10\left(\mathrm{~s}, \mathrm{CH}_{3}\right), 6.80\left(\mathrm{~d}, \mathrm{H}_{4}\right.$ or $\mathrm{H}_{5}, \mathrm{~J}=$ $7 \mathrm{~Hz}$ ), 7.15 (d, $\mathrm{H}_{5}$ or $\left.\mathrm{H}_{4}, \mathrm{~J}=7 \mathrm{~Hz}\right), 11.25$ (s,OH).

$\mathrm{m} / \mathrm{z}$ (relative abundance): $184[\mathrm{M}]^{+}$. (35); main fragments: 166(100), elimination of $\mathrm{H}_{2} \mathrm{O} ; 151(50)$, elimination of $\mathrm{CH}_{3} ; 123(82)$, elimination of $\mathrm{CO}$.

Product (2)

$\left[{ }^{1} \mathrm{H}\right]$ NMR $\delta(\mathrm{ppm}): 5.75\left(\mathrm{~s}, \mathrm{CH}_{2}\right), 6.70\left(\mathrm{~d}, \mathrm{H}_{4}\right.$ or $\mathrm{H}_{5}, \mathrm{~J}=$ $7 \mathrm{~Hz}), 7.15$ (d, $\mathrm{H}_{4}$ or $\left.\mathrm{H}_{5}, \mathrm{~J}=7 \mathrm{~Hz}\right), 9.50(\mathrm{~s}, \mathrm{OH})$.

$\mathrm{m} / \mathrm{z}$ (relative abundance): $182[\mathrm{M}]^{+}$. (30); main fragments: 152(100), elimination of $\mathrm{CH}_{2}=\mathrm{O} ; 124(34)$, elimination of $\mathrm{CO}$; 96(42), elimination of $\mathrm{CO}$.

In order to confirm the GC-MS results, both products (1) and (2) were derivated with a sylilation agent.

Following results were obtained after treatment:

Product (1)

$\mathrm{m} / \mathrm{z}$ (relative abundance): $400[\mathrm{M}]^{+} . \quad$ (18); main fragments: 385(100), elimination of $\mathrm{CH}_{3} ; 355(33)$, elimination of $\mathrm{CH}_{3}-\mathrm{Si}^{+} \mathrm{H}_{2} ; 282(10)$, elimination of $\mathrm{HCOOSi}\left(\mathrm{CH}_{3}\right)_{3} ; 73(89),{ }^{+} \mathrm{Si}\left(\mathrm{CH}_{3}\right)_{3}$.

Product (2)

$\mathrm{m} / \mathrm{z}$ (relative abundance): $326[\mathrm{M}]^{+}$. (16); main fragments: 311(50), elimination of $\mathrm{CH}_{3} ; 281(100)$, elimination of $\mathrm{CH}_{3}-\mathrm{Si}^{+} \mathrm{H}_{2} ; 73(58),{ }^{+} \mathrm{Si}\left(\mathrm{CH}_{3}\right)_{3}$.

These results fit well with a double sylilation of product (2) and a triple sylilation of product (1). From these results the following stuctures were deduced.<smiles>COc1c(O)ccc(O)c1C(=O)O</smiles>

Product (1)<smiles>O=C1OCOc2c(O)ccc(O)c21</smiles>

Product (2)

\subsection{Dicamba photolysis in adsorbed phase.}

Kinetics of disappearance and evolution of UV spectrum. Disappearance of solid dicamba is improved in presence of clays and to a less extend in presence of ferric oxide (Figure 3 ) The evolution of UV spectrum is not the same as in aqueous solution (Figure 4). However, in both cases an increase of absorbance was observed within the whole spectrum. A continuous increase of absorbance in visible area occurs. In the case of clay, the solid was initially white. After 4 hours about $10 \%$ of dicamba has disappeared and the solid become yellowbrown. After 87 hours (40\% conversion), it was darkbrown. 
In contrast to aqueous solutions, a huge number of photoproducts were detected by HPLC/UV chromatography. Some of them have shorter retention time than dicamba but several peaks elute after it. Their amounts are very small and only three photoproducts eluting after dicamba (r.t. $=26,64$, and $67 \mathrm{~min}$ ) reached a concentration sufficient to record their UV spectra. They absorb at $228-271 \mathrm{~nm}, 222-281 \mathrm{~nm}$ and $220-262 \mathrm{~nm}$, respectively.

Identification of photoproducts. Only benzoic acid has been identified by comparing the UV spectrum and the HPLC retention time ( $26 \mathrm{~min})$ with that of an authentic sample. The other compounds were identified by GC/MS analysis. They are listed in Table 1 . Their structures correspond to decarboxylation, methylation, chlorination, dechlorination and hydroxylation products.

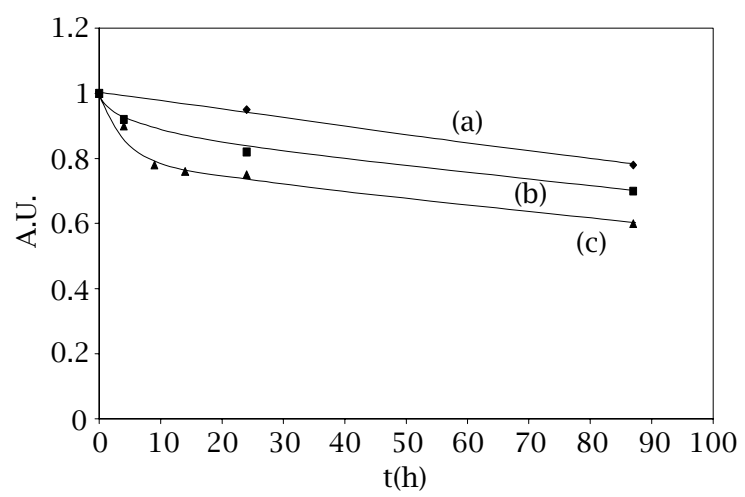

Figure 3. Phototransformation of dicamba in solid phase (a) without solid, (b) in presence of ferric oxide and (c) in presence of a clay (laponite).

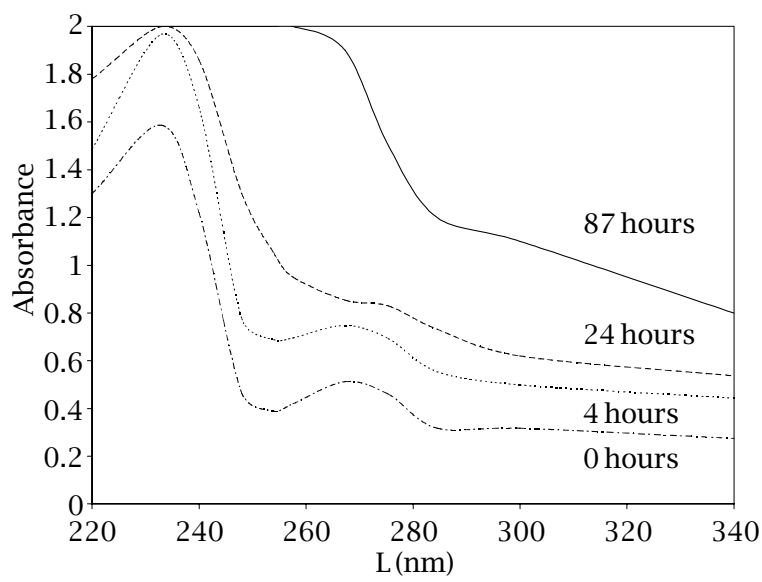

Figure 4. Evolution of the UV spectrum of dicamba adsorbed on laponite as a function of irradiation time.

The compound which has HPLC retention time equal to $64 \mathrm{~min}$ is most probably 2,5-dichloroanisole (r.t. $=15.1 \mathrm{~min}$ in GC chromatogram) because its UVspectrum is similar to 2,5-dichlorophenol and its retention time is about $1 \mathrm{~min}$ longer. In this case, it can be concluded that decarboxylation is a primary reaction. This hypothesis is corroborated by the formation of $\mathrm{CO}_{2}$ at the beginning of the reaction. Without clay, de- carboxylation is not detected. The two main intermediates detected in the aqueous photolysis are also present in trace concentration. The appearance of visible colour when dicamba is photolysed in the solid phase could be due to the formation of humic substances.

Table 1. GC retention times, $m / z$ and structure of intermediate products detected by GC/MS in the phototransformation of dicamba adsorbed on laponite.

\begin{tabular}{|c|c|c|c|}
\hline Number & r.t. & $\mathrm{m} / \mathrm{z}$ & Structure \\
\hline I & 11.9 & 122 & \\
\hline II & 12.6 & 162 & \\
\hline III & 13.5 & 124 & \\
\hline IV & 14.9 & 158 & \\
\hline V & 15.1 & 176 & \\
\hline VI & 15.5 & 138 & \\
\hline VII & 16.9 & 186 & \\
\hline VIII & 17 & 186 & \\
\hline IX & 17.6 & 168 & \\
\hline $\mathrm{X}$ & 17.8 & 192 & \\
\hline XI & 18.9 & 182 & \\
\hline XII & 19.2 & 152 & \\
\hline XIII & 21.3 & 184 & \\
\hline XIV & 24 & 234 & \\
\hline $\mathrm{XV}$ & 27 & 254 & \\
\hline
\end{tabular}

\section{DISCUSSION AND MECHANISMS}

4.1. Phototransformation in aqueous solution. Phototransformation of (1) is explained by a double photohydrolysis involving the intermediate formation of a substituted 4-chlorophenol, since it is a reaction commonly observed with chloroaomatic derivatives [6]. 
Most probably the substituted 4-chlorophenol cannot accumulate in solution: if 4-chlorophenol is compared with 1,4-dichlorobenzene, the former absorbs at longer wavelength, it has a higher molecular ab- sorption coefficient and a significantly higher quantum yield ( $\phi=0.7-0.9$ for 4-chlorophenol; $\phi=0.05$ for 1,4-dichlorobenzene). However no information is available about the order of elimination of $\mathrm{Cl}$ atoms.

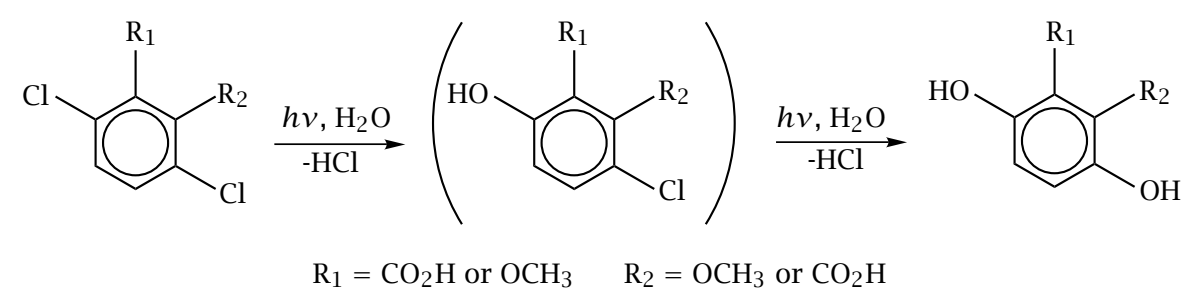<smiles>Oc1ccc(Cl)cc1</smiles><smiles>O=C1C=CCCC1</smiles><smiles>CC=CC</smiles><smiles>O=C1C=CC(=[O+][O-])C=C1</smiles><smiles>[CH2]O</smiles><smiles>O=C1C=CC(=O)C=C1</smiles>

Product (2) results from an oxidation, but it was experimentally proved that it is not formed from (1). It is assumed to result from the photooxidation of the intermediate substituted 4-chlorophenol. Actually it was previously observed by Grabner et al. that the carbene primarly formed in the photolysis of 4-chlorophenol is oxidized into benzoquinone [9]. By analogy with the degradation of 4-chlorophenol, the formation of product (2) can be explained by the mechanism presented in Scheme 1.<smiles>COc1c(Cl)ccc(O)c1C(=O)O</smiles><smiles>O=C(O)C1=C(OCO)C(=O)C=CC1=O</smiles><smiles>O=C1OCOc2c(O)ccc(O)c21</smiles>

product (2)

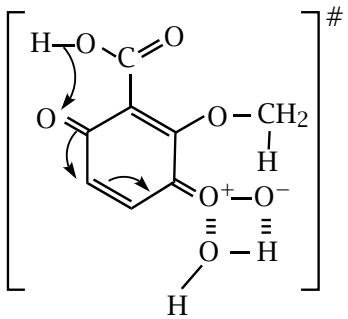

The first step is most likely the formation of carbene intermediate which is oxidized to peroxo. Then a concerted mechanism leads to product (2).

4.2. Phototransformation in the solid phase. The photolysis of dicamba is much slower in the microcrystalline form than in the adsorbed state on clay. It is attributed to both a better dispersion and interactions between subtrate and support. In the absence of support, the herbicide is in the microcrystalline form. Surface exposed to light is reduced and a screen effect is expected for the central part of microcrystals. The use of ferric oxide as the adsorbent increases the dispersion but introduces a screen effect by the absorbing support. So it is not surprising that a better efficiency is obtained on laponite that contains no iron salt.

The presence of decarboxylation products and the formation of $\mathrm{CO}_{2}$ in presence of clay denotes that dicamba interact with clay through the carbonyl group and that a photoinduced charge transfer occurs [11]. This photophysic phenomenon is probably at the origin of decarboxylation, since this reaction does not occur in the absence of clay. A mechanism is proposed as in Scheme 2. 


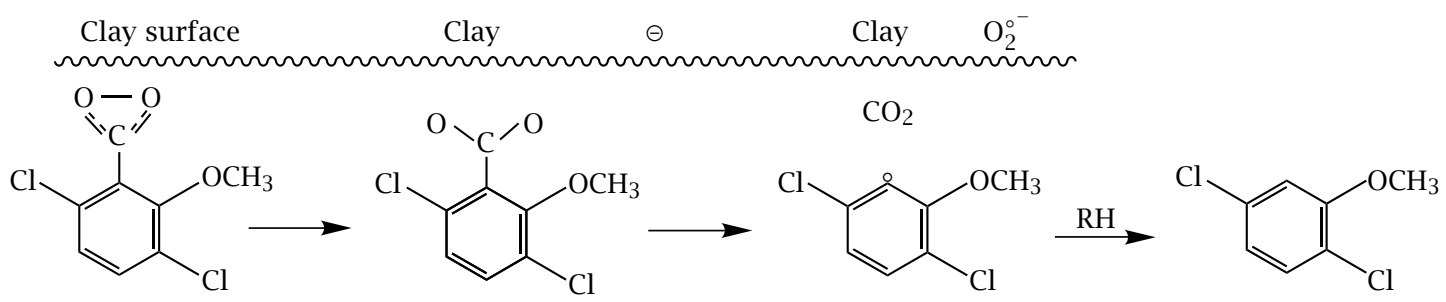

Scheme 2

The reactions of dechlorination and hydroxylation can be explained by the presence of residual water on solid which can polarise $\mathrm{O}-\mathrm{CH}_{3}$ and $\mathrm{C}-\mathrm{Cl}$ bond as represented in the following:

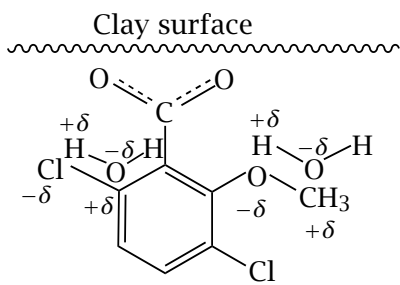

The photolysis of dicamba in aqueous solution and adsorbed on soil constituents (or used as a solid), involves different mechanisms. In the solid phase, a more important number of intermediate products are present, pointing out a more complex pathway. Most of photoproducts correspond to reduction. They probably result from the formation of radicals followed by an oxido-reductive process. The translational motion of the organic molecules adsorbed on silica was experimentally proved by Bauer et al. [12]. Similar radical oxido-reductive reactions were recently pointed out with pentachlorophenol irradiated in the solid state [13]. In the present case the formation of most of identified products can be explained by the formation of radicals such as $\mathrm{Cl}^{\circ}, \mathrm{RCOO}^{\circ}, \mathrm{R}^{\prime} \mathrm{O}^{\circ}, \mathrm{R}^{\prime \prime}, \mathrm{CH}_{3}{ }^{\circ}$ followed by recombination or oxido-reductive reaction.

The presence of a small amount of the products (1) and (2) in adsorbed phase photolysis may result either from traces of adsorbed water or from a heterolytic substitution of $\mathrm{Cl}$ with $\mathrm{OH}$ of silanol groups on the clay surface.

\section{CONCLUSION}

The photochemical transformation of dicamba in aqueous solution implies the involvement of water molecules and it leads to dechlorination.

Reactions are different and much more complex when dicamba is irradiated in the solid state without added water. The dispersion on a clay significantly increases the photoreaction rate compared to microcrystal form or dispersion on ferric oxide. Many photoproducts were identified. They mainly result from decarboxylation and reduction. They are attributed to charge transfer and radical reactions.

The present work shows that the photochemical behaviour of dicamba in environmental conditions is very complex. A dry soil has a different behaviour than a wet soil, both on the kinetics and on the pathway of phototransformation. The nature of soil also plays a role.

\section{REFERENCES}

[1] C. Tomlin (ed.), The Pesticide Manual, 10th edn British Crop Corporation Council (The Bath Press, Bath, UK, 1994), pp. 298-99.

[2] A. M. Fogarty and O. Tuovinen, J. Indus. Microbiol. 14 (1995), 365.

[3] J. P. Krueger, R. G. Butz, and D. J. Cork, J. Agric. Food Chem. 36 (1991), 995.

[4] E. W. Pavel, A. R. Lopez, D. F. Berry, E. P. Smith, R. B. Reneau, Jr., and S. Mostaghini, Wat. Res. 33 (1999), 87.

[5] F. Bourgine, J. Chapman, and S. Martin, Techniques, Sciences, Méthodes, Génie urbain, Génie rural 7-8 (1997), p. 23.

[6] A. Tissot, P. Boule, and J. Lemaire, Chemosphere 14 (1985), 1789.

[7] K. Oudjehani and P. Boule, J. Photochem. Photobiol. A: Chem. 68 (1992), 363.

[8] E. Lipczynska-Kochany and J. R. Bolton, J. Chem. Soc. Chem. Commun. (1990), 1596.

[9] G. Grabner, C. Richard, and G. Köhler, J. Am. Chem. Soc. 116 (1994), 11470.

[10] A. P. Durand, R. G. Brown, D. Worrall, and F. Wilkinson, J. Photochem. Photobiol. A: Chem. 96 (1996), 35

[11] J. Thomas, Chem. Rev. 93 (1993), 301

[12] R. K. Bauer, R. Borenstein, P. de Mayo, K. Okada, M. Rafalska, W. R. Ware, and K. C. Wu, J. Am. Chem. Soc. 104 (1982), 4635.

[13] P. Piccinini, P. Pichat, and C. Guillard, J. Photochem. Photobiol. A: Chem. 119 (1998), 137. 


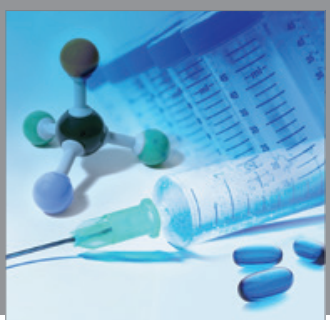

International Journal of

Medicinal Chemistry

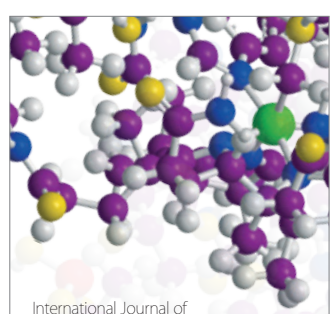

Carbohydrate Chemistry

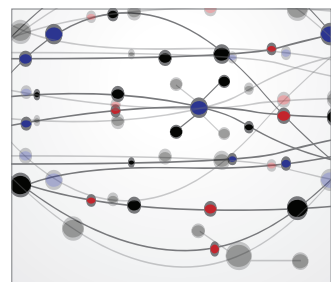

The Scientific World Journal
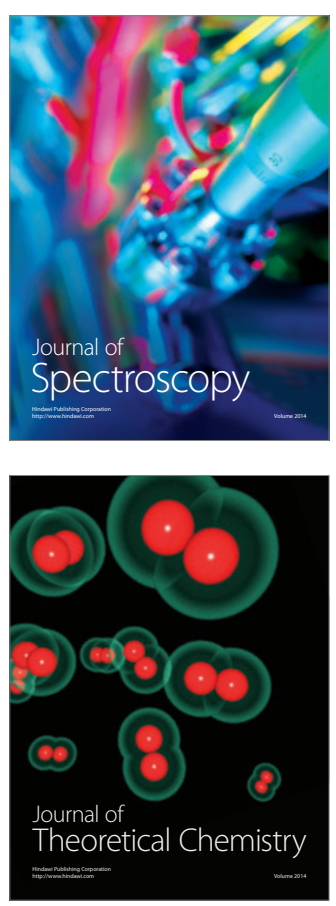
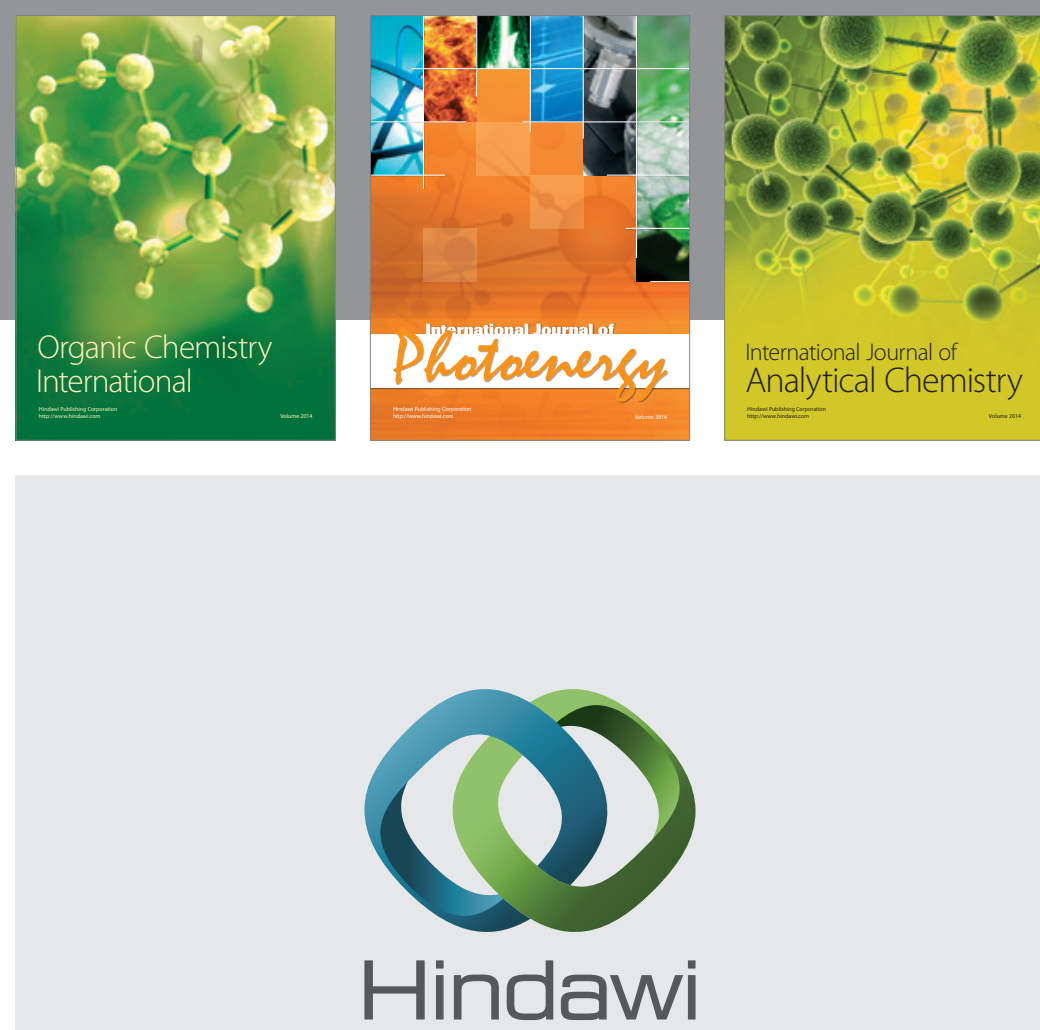

Submit your manuscripts at

http://www.hindawi.com
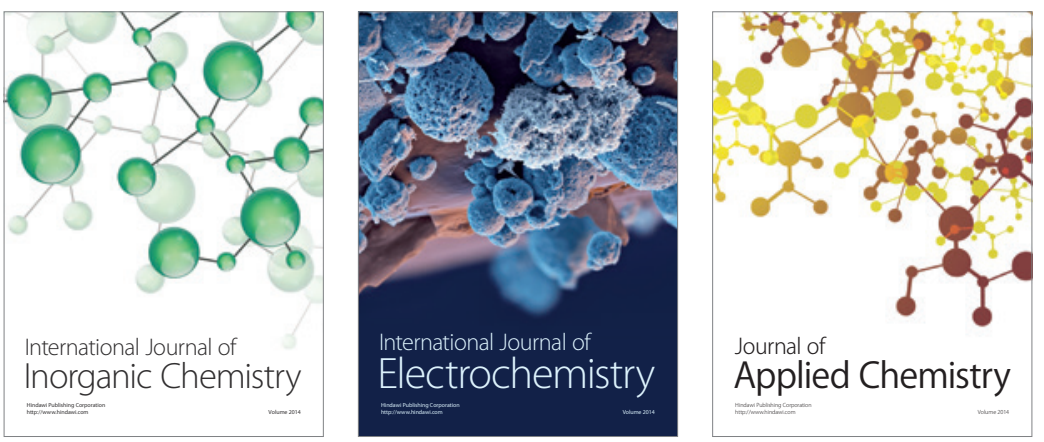

Journal of

Applied Chemistry
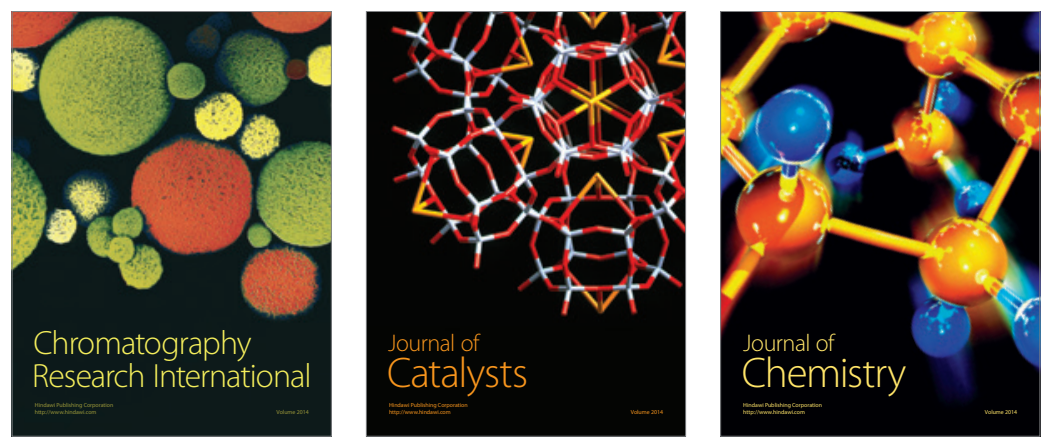
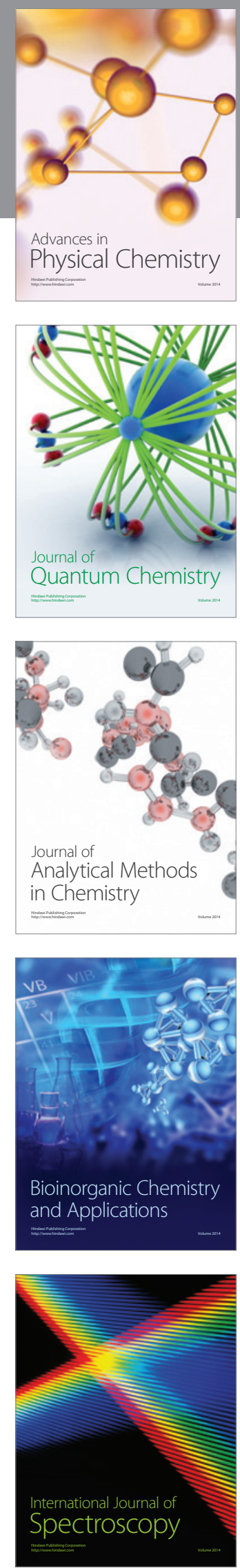